\author{
SANDIA REPORT \\ SAND2007-0779 \\ Unlimited Release \\ Printed February 2007
}

\title{
VISAR Validation Test Series at the Light Initiated High Explosive (LIHE) Facility
}

Timothy Covert

Prepared by

Sandia National Laboratories

Albuquerque, New Mexico 87185 and Livermore, California 94550

Sandia is a multiprogram laboratory operated by Sandia Corporation,

a Lockheed Martin Company, for the United States Department of Energy's

National Nuclear Security Administration under Contract DE-AC04-94AL85000.

Approved for public release; further dissemination unlimited. 
Issued by Sandia National Laboratories, operated for the United States Department of Energy by Sandia Corporation.

NOTICE: This report was prepared as an account of work sponsored by an agency of the United States Government. Neither the United States Government, nor any agency thereof, nor any of their employees, nor any of their contractors, subcontractors, or their employees, make any warranty, express or implied, or assume any legal liability or responsibility for the accuracy, completeness, or usefulness of any information, apparatus, product, or process disclosed, or represent that its use would not infringe privately owned rights. Reference herein to any specific commercial product, process, or service by trade name, trademark, manufacturer, or otherwise, does not necessarily constitute or imply its endorsement, recommendation, or favoring by the United States Government, any agency thereof, or any of their contractors or subcontractors. The views and opinions expressed herein do not necessarily state or reflect those of the United States Government, any agency thereof, or any of their contractors.

Printed in the United States of America. This report has been reproduced directly from the best available copy.

Available to DOE and DOE contractors from

U.S. Department of Energy

Office of Scientific and Technical Information

P.O. Box 62

Oak Ridge, TN 37831

Telephone: $\quad$ (865) 576-8401

Facsimile: (865) 576-5728

E-Mail: reports@adonis.osti.gov

Online ordering: http://www.osti.gov/bridge

Available to the public from

U.S. Department of Commerce

National Technical Information Service

5285 Port Royal Rd.

Springfield, VA 22161

Telephone: $\quad$ (800) 553-6847

Facsimile: (703) 605-6900

E-Mail: $\quad$ orders@ntis.fedworld.gov

Online order: $\quad$ http://www.ntis.gov/help/ordermethods.asp?loc=7-4-0\#online

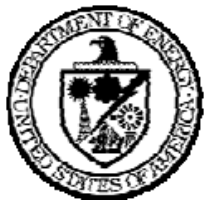


SAND2007-0779

Unlimited Release

Printed February 2007

\title{
VISAR Validation Test Series at the Light Initiated High Explosive (LIHE) Facility
}

\author{
Timothy Covert \\ Explosive Projects and Diagnostics \\ Sandia National Laboratories \\ P.O. Box 5800 \\ Albuquerque, New Mexico 87185-MS1454
}

\begin{abstract}
A velocity interferometer system for any reflector (VISAR) was recently deployed at the light initiated high explosive facility (LIHE) to measure the velocity of an explosively accelerated flyer plate. The velocity data from the flyer plate experiments, using the vendor's fringe constant of $100 \mathrm{~m} / \mathrm{s} /$ fringe, were consistently lower than model predictions. The goal of the VISAR validation test series was to confirm the VISAR system fringe constant. A low velocity gas gun was utilized to impact and accelerate a target at the LIHE facility. VISAR velocity data from the accelerated target was compared against an independent velocity measurement. The data from this test series did in fact reveal the fringe constant was significantly higher than the vendor's specification. The correct fringe constant for the LIHE VISAR system has been determined to be $123 \mathrm{~m} / \mathrm{s} /$ fringe.
\end{abstract}




\section{ACKNOWLEDGMENTS}

The author would like to acknowledge the significant contributions of the following personnel.

Kevin Fleming and Chris Colburn were responsible for the assembly and deployment of the VISAR system at the Light Initiated High Explosive Facility (LIHE). They were also instrumental in the development of the optical displacement detectors.

Daniel Sandoval was the designer and owner of the gas gun used in this test series.

Carolyn Trexler was responsible for the installation and operation of the gas gun at the LIHE Facility.

The entire LIHE team made significant contributions to the success of this test series. Edward Mulligan provided instrumentation support and developed the instrumentation triggering scheme. John Liwski provided VISAR and instrumentation support. Daniel Dow provided test and hardware fabrication support. 


\section{CONTENTS}

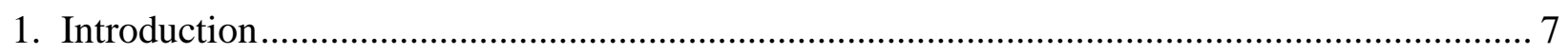

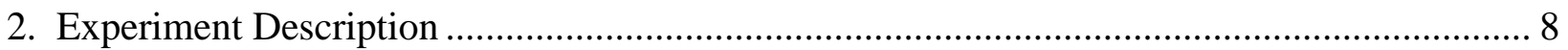

2.1. Hardware Description ........................................................................................ 8

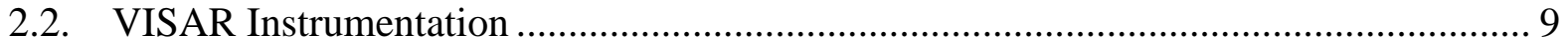

2.3. Optical Displacement Detector Instrumentation..................................................... 9

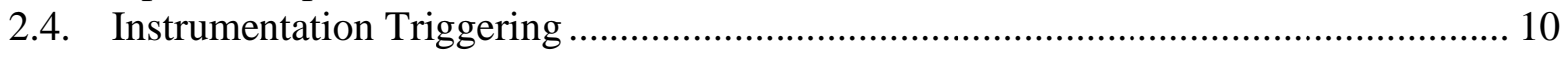

2.5. Impact Conditions ........................................................................................................ 11

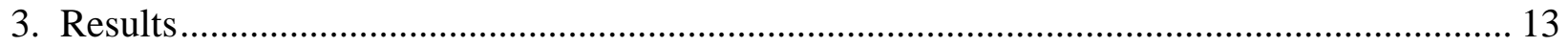

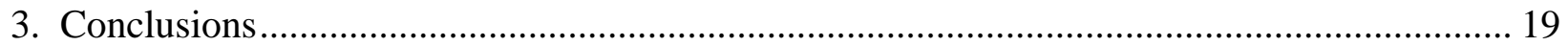

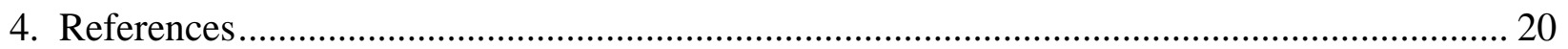

Appendix A: Hardware Engingeering Drawings ..................................................................... 21

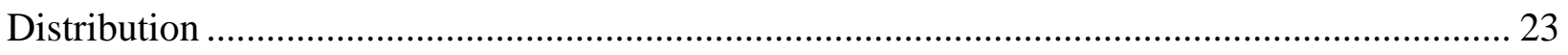

\section{FIGURES}

Figure 1. Gas gun used to generate target acceleration. ................................................................. 8

Figure 2. VISAR Validation Hardware ................................................................................... 9

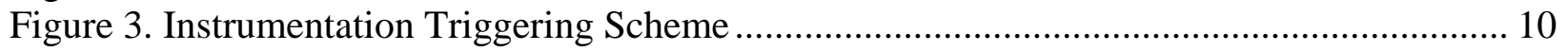

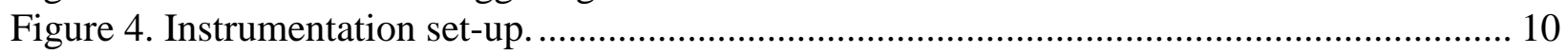

Figure 5. Gas gun velocity versus pressure (Sandoval) ............................................................... 11

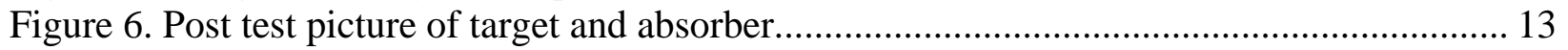

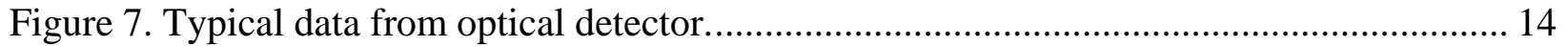

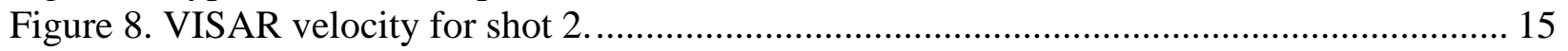

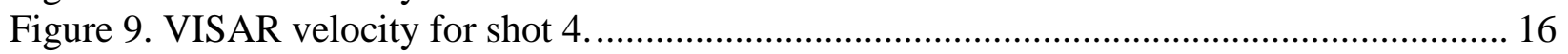

Figure 10. VISAR data overlay with light intensity monitor. (Note: intensity data scaled and

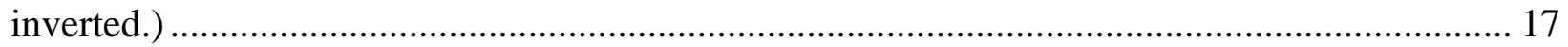

Figure 11. Integrated velocity data shows 5mm of target displacement....................................... 18

\section{TABLES}

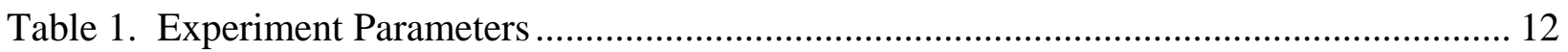

Table 2. Optical displacement detector velocity data ..................................................................... 15

Table 3. VISAR velocity comparison to optical displacement detector velocity.......................... 16 


\section{NOMENCLATURE}

$\begin{array}{ll}\text { DOE } & \text { Department of Energy } \\ \text { LIHE } & \text { Light Initiated High Explosive } \\ \text { SNL } & \text { Sandia National Laboratories } \\ \text { VISAR } & \text { Velocity interferometer system for any reflector } \\ \text { X-Flyer } & \text { Explosively accelerated flyer plate } \\ & \\ \text { GHz } & \text { Giga Hertz } \\ \mathrm{MHz} & \text { Mega Hertz } \\ \mathrm{m} / \mathrm{s} & \text { meters per second } \\ \mathrm{m} / \mathrm{s} / \mathrm{fringe} & \text { meters per second per fringe } \\ \text { psi } & \text { pounds per square inch } \\ \text { VDC } & \text { volts - direct current }\end{array}$




\section{INTRODUCTION}

The Light Initiated High Explosive (LIHE) facility recently completed a Phase I test series to develop an explosively accelerated flyer plate (X-Flyer). The X-Flyer impulse technique consists of first spraying a thin layer of silver acetylide silver nitrate explosive onto a thin flyer plate. The explosive is then initiated using an intense flash of light. The explosive detonation accelerates the flyer across a small air gap towards the test item. The impact of the flyer with the test item creates a shock pulse and an impulsive load in the test unit. The goal of Phase I of the X-Flyer development series was to validate the technique theory and design process. One of the key parameters that control the shock pulse and impulsive load is the velocity of the flyer at impact. To measure this key parameter, a velocity interferometer system for any reflector (VISAR) was deployed at the LIHE facility.

The VISAR system was assembled by Sandia personnel from the Explosive Projects and Diagnostics department. The VISAR was a three leg, push-pull system using a fixed delay cavity. The primary optical components consisted of a delay bar and stand off that holds the airreference mirror. When this component was ordered 2 years ago, a fringe constant of 100 $\mathrm{m} / \mathrm{s} /$ fringe for a $532 \mathrm{~nm}$ laser was specified. The fabrication/assembly vendor went out of business shortly after delivering the component and did not deliver the certification papers with the component. The vendor documentation to verify the fringe constant was not made available to Sandia. VISAR systems were generally not calibrated because the fringe constant could be determined from a known glass index of refraction and length. The VISAR system was deployed at the LIHE facility using the specified $100 \mathrm{~m} / \mathrm{s} /$ fringe.

The Phase I X-Flyer development series was completed successfully measuring flyer

velocities using the VISAR system. However flyer velocity measurements were on average 18\% lower than analytical model predictions. In an effort to resolve the consistently slow velocity data, the VISAR data was under scrutiny. The purpose of the LIHE VISAR validation test series is to verify the velocity data taken with the VISAR system. 


\section{EXPERIMENT DESCRIPTION}

A small table top mounted, gas actuated gun was installed at the LIHE facility as shown in Figure 1. Pressurized gas was used to accelerate a projectile into a target. The impact accelerated the target into a soft catch. As the target accelerated, the velocity was measured using the facility VISAR. An independent optical displacement detector was developed to corroborate the VISAR data. Comparison of the VISAR data to the optical displacement detector data provided validation of the VISAR fringe constant.

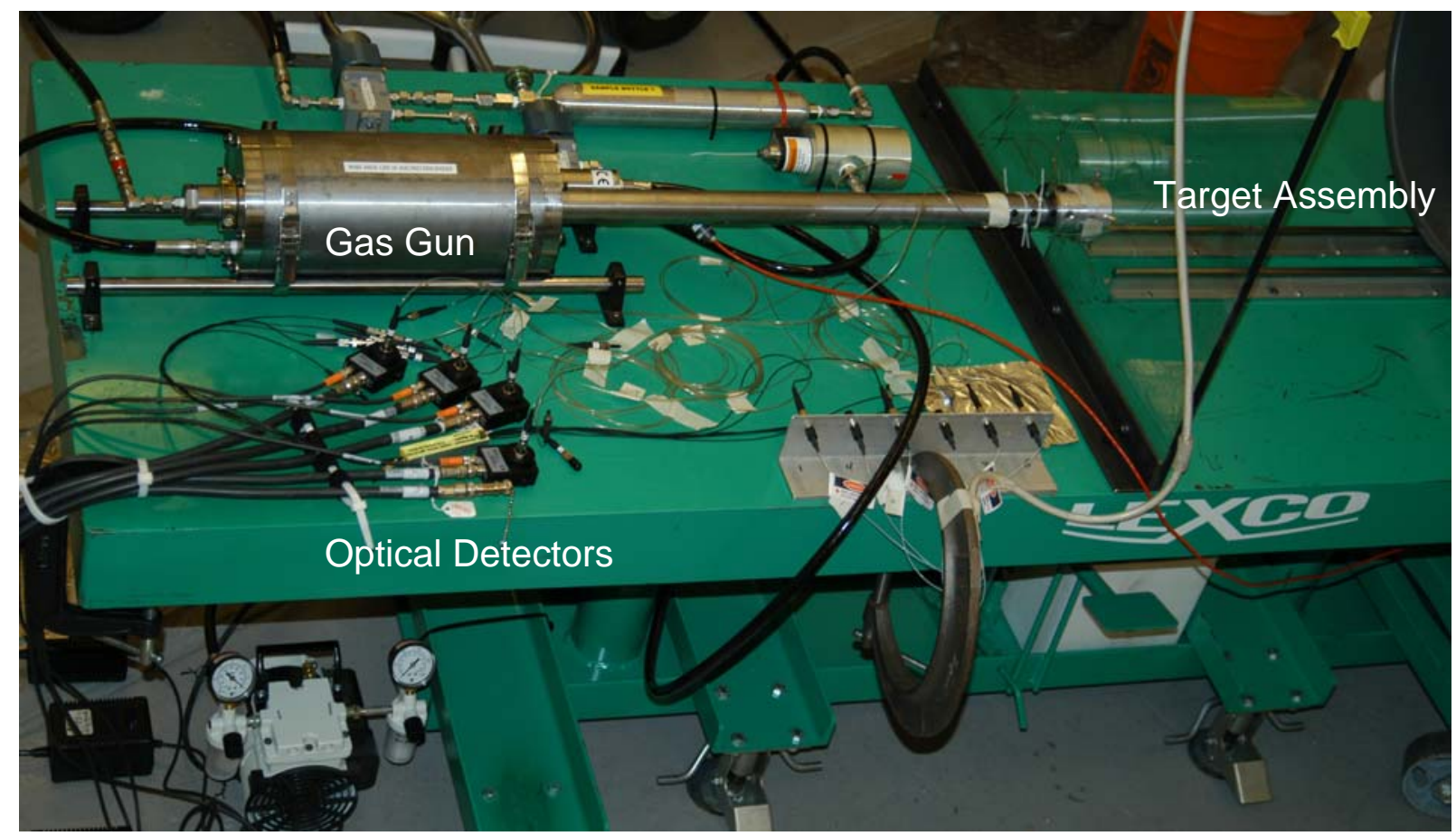

Figure 1. Gas gun used to generate target acceleration.

\subsection{Hardware Description}

A compressed gas actuated gun was designed by personnel from the Explosive Projects and Diagnostics department. This gun was deployed at the LIHE facility for the purpose of accelerating a steel projectile to impart velocity to the target. The velocity of the projectile was not measured and was not important. Only the velocity of the target was measured.

The projectile impacted a polycarbonate absorber/buffer which was glued into the aluminum target as shown in Figure 2. The VISAR probes, which were secured into the target fixture, measured the velocity of the target as it accelerated away from the probe. Two grooves were machined into the outer surface of the target. The optical displacement detectors measured changing light reflection as the grooves in the target passed by the detectors. The optical displacement detectors were secured into the target fixture. The engineering drawings for the fixture and target are included in the appendix. 


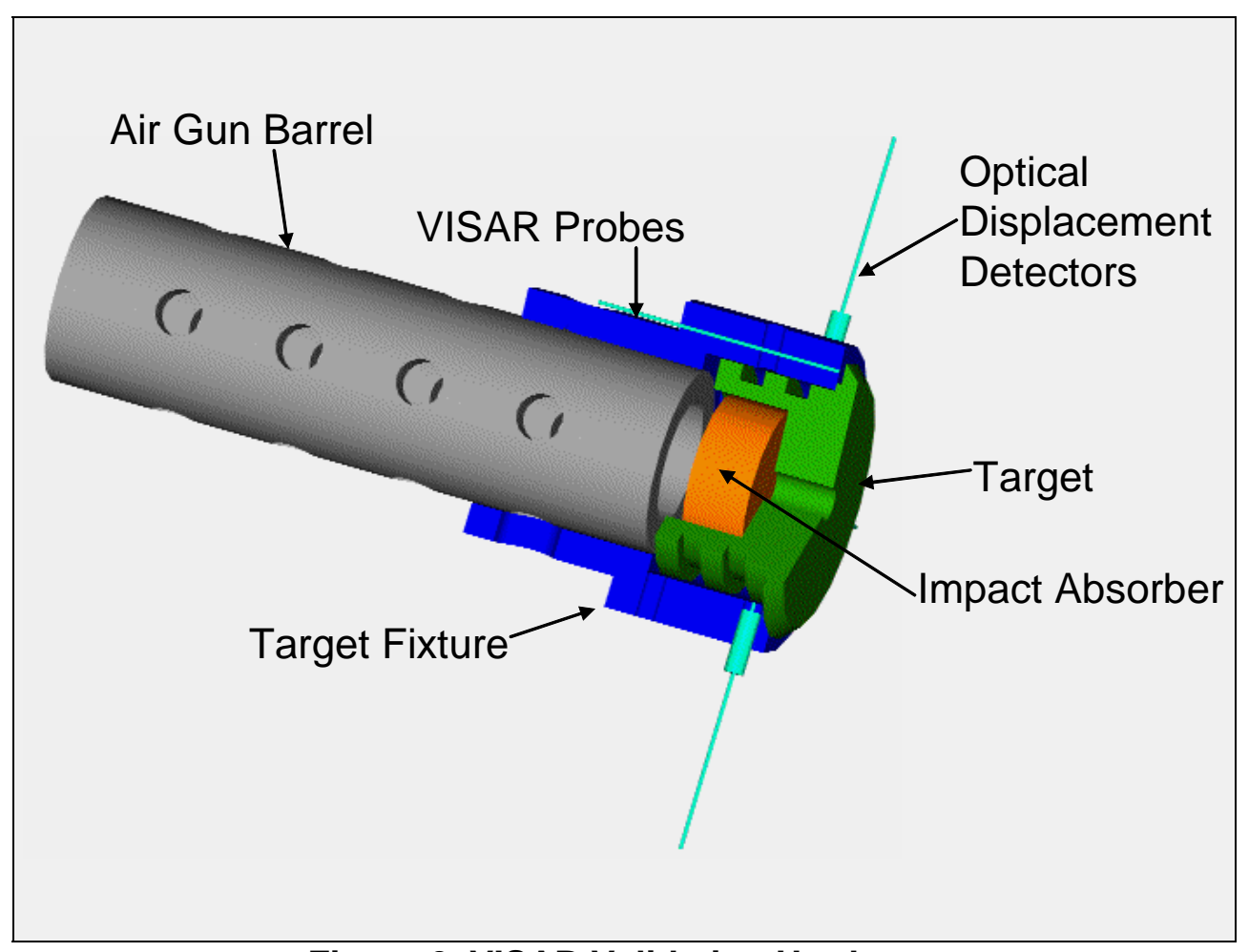

Figure 2. VISAR Validation Hardware

\subsection{VISAR Instrumentation}

The LIHE facility VISAR system has three legs or three measurement channels. However the same delay bar was used for all three legs. Therefore it was only necessary to determine the fringe constant once which must be identical for all three legs. One VISAR velocity was recorded for the validation test series. The VISAR probe used a $100 \mu \mathrm{m}$ send and receive fiber glued in a 0.032 inch hypodermic needle. The VISAR probe measured the velocity of the outer edge of the aluminum target. Normally this type of VISAR probe has a measurement range of approximately $3 \mathrm{~mm}$. To increase the light return and thereby increase the measurement range, retro-reflective tape was applied to the target surface being measured by the VISAR probe. It was necessary for the measurement range to be greater than the acceleration distance of the target.

The VISAR configuration measured the velocity of the target as it accelerated away from the probe. Since the target never impacted the probe, a single probe was reused for the entire test series. The maximum laser light return and consequently best quality data occurred when the target was close to the probe, within $1 \mathrm{~mm}$. By accelerating the target away from the probe, the best data quality occurred during the period of greatest acceleration.

\subsection{Optical Displacement Detector Instrumentation}

The laser output from the other two VISAR legs was used for the optical displacement detectors. The original test plan called for the two laser outputs to be split for four optical detectors. However, the light loss associated with the splitter was significant. After the first shot, which failed to trigger the instrumentation system, the splitter was removed and only two optical detectors were used. The optical detectors used the same probe type as the VISAR probe. The 
probe was inserted into the target fixture and its standoff was adjusted to achieve maximum light return from the target. To maximize the light return, the surface of the aluminum target was scuffed to achieve a diffuse surface. As the target moved past the detectors, the light return from the grooves was significantly less. To minimize the light return from the grooves, they were painted with Dykem Blue layout fluid. The light returned from the detector probes were measured using optical detectors with a bandwidth of $150 \mathrm{MHZ}$.

\subsection{Instrumentation Triggering}

The initial planned instrumentation triggering scheme used the optical detector output as the triggering source. This scheme proved to be unreliable. Instead a break switch scheme was implemented. A piece of $0.9 \mathrm{~mm}$ pencil lead was inserted through two vent holes in the target fixture. This bare graphite was electrically isolated from the fixture. The electrical schematic of the break switch trigger is shown in Figure 3. Figure 4 shows the trigger inserted into the fixture. When the projectile shattered the graphite, a 7VDC falling trigger pulse was generated and used to trigger the instrumentation.

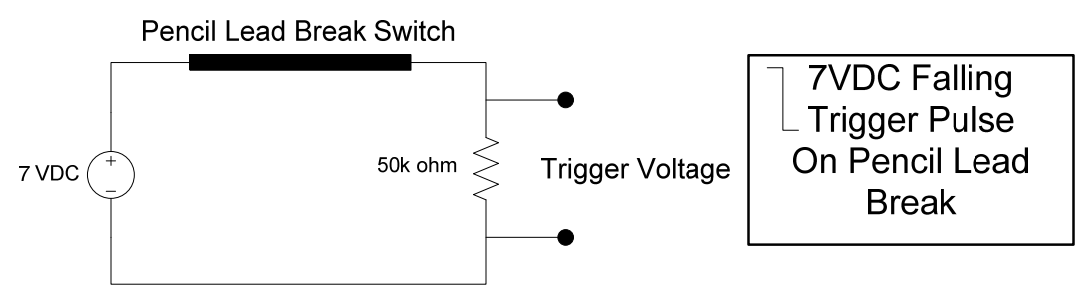

Figure 3. Instrumentation Triggering Scheme

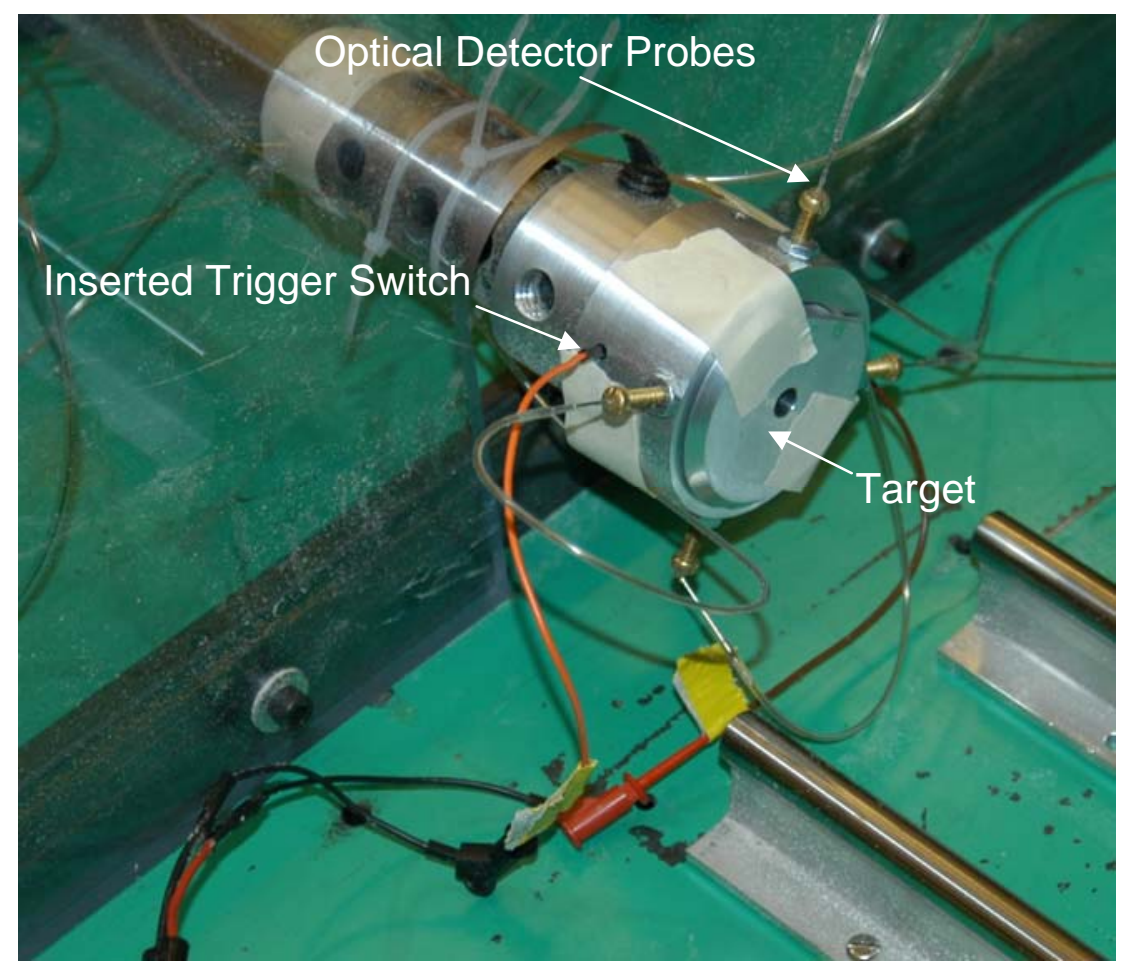

Figure 4. Instrumentation set-up. 


\subsection{Impact Conditions}

The fringe constant was believed to be $100 \mathrm{~m} / \mathrm{s} /$ fringe prior to conducting this test series. Consequently it was desirable to measure the velocity with approximately a full fringe, or near $100 \mathrm{~m} / \mathrm{s}$. A range of velocities were to be measured between $70 \mathrm{~m} / \mathrm{s}$ and $350 \mathrm{~m} / \mathrm{s}$.

The impact velocity of the projectile was calculated to achieve the target velocity of interest. The impact of the projectile into the absorber/buffer resulting in target motion was modeled using the one-dimensional hydrocode KOWIN. Since this impact was not onedimensional, the varying cross-sections were modeled using a uniform cross-section. The lengths of the components were scaled in KOWIN to preserve component mass. The component mass of the projectile, absorber, and target were 186gr, 12gr and 80gr respectively. For determining the bulk velocities, the one-dimensional approximations were adequate. Therefore KOWIN was used to predict the required projectile velocity to achieve the desired target velocity. Since the absorber is glued into the target, KOWIN assumed they would separate upon impact. If they remained intact, the resultant velocity will be lower than predicted. Calculated velocities were verified using conservation of momentum.

Based on the required projectile velocity, the gun pressure curve shown in Figure 5 was used to determine the required driving pressure. The target velocity goals, projectile velocity, and driving pressure are shown in Table 1 . The actual target velocities achieved were not important as long as they were within the range of interest.

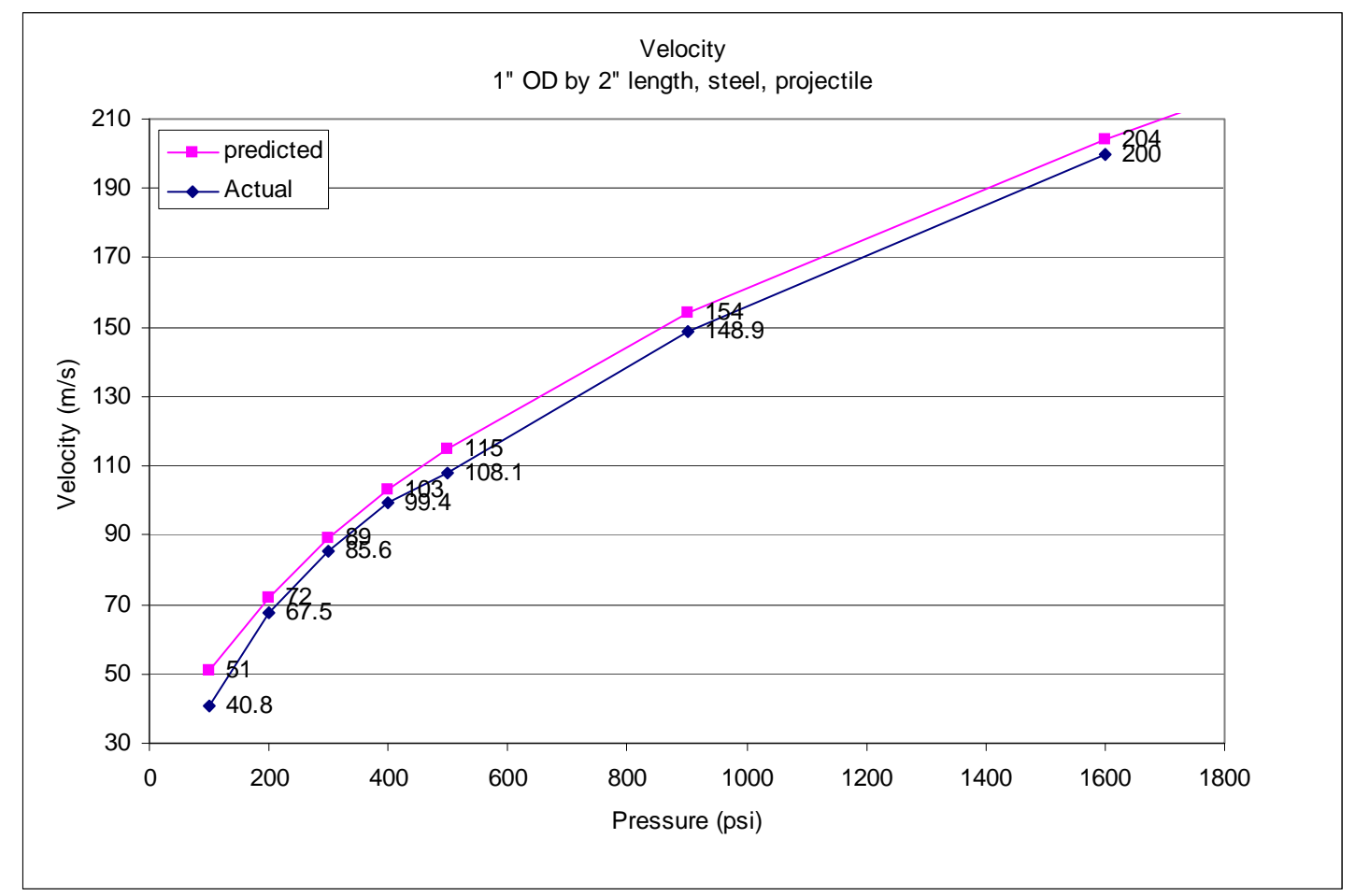

Figure 5. Gas gun velocity versus pressure (Sandoval) 
Table 1. Experiment Parameters

\begin{tabular}{|c|c|c|}
\hline Target Velocity - Goal (m/s) & Projectile Velocity (m/s) & Gun Pressure (psi) \\
\hline 100 & 75 & 250 \\
\hline 150 & 113 & 570 \\
\hline 200 & 150 & 900 \\
\hline 300 & 225 & 1880 (est.) \\
\hline
\end{tabular}




\section{RESULTS}

The aluminum target was designed to be lightweight to minimize the projectile impact velocity and driving pressure. Due to schedule and budget constraints, only a minimal hardware set was machined. It was believed that by using the soft catch, the targets would be reusable. The polycarbonate absorber/buffer was intended to be the sacrificial consumable. The soft catch did adequately stop the target without damage. However the projectile retained velocity after impact and subsequently impacted the target a second time. This off-axis second impact damaged the target in each test. Fortunately the damaged portion of the target was machined away without loss of functionality as shown in Figure 6. The pressure exerted by the crushing polycarbonate absorber also resulted in distortion of the aluminum target. The groove width elongated slightly during the test series and was measured to ensure accurate velocity determination. Due to hardware damage to the minimal hardware set and to triggering issues, only two data shots (shots two and four) were successfully completed. For shots one and three, no data was recorded.

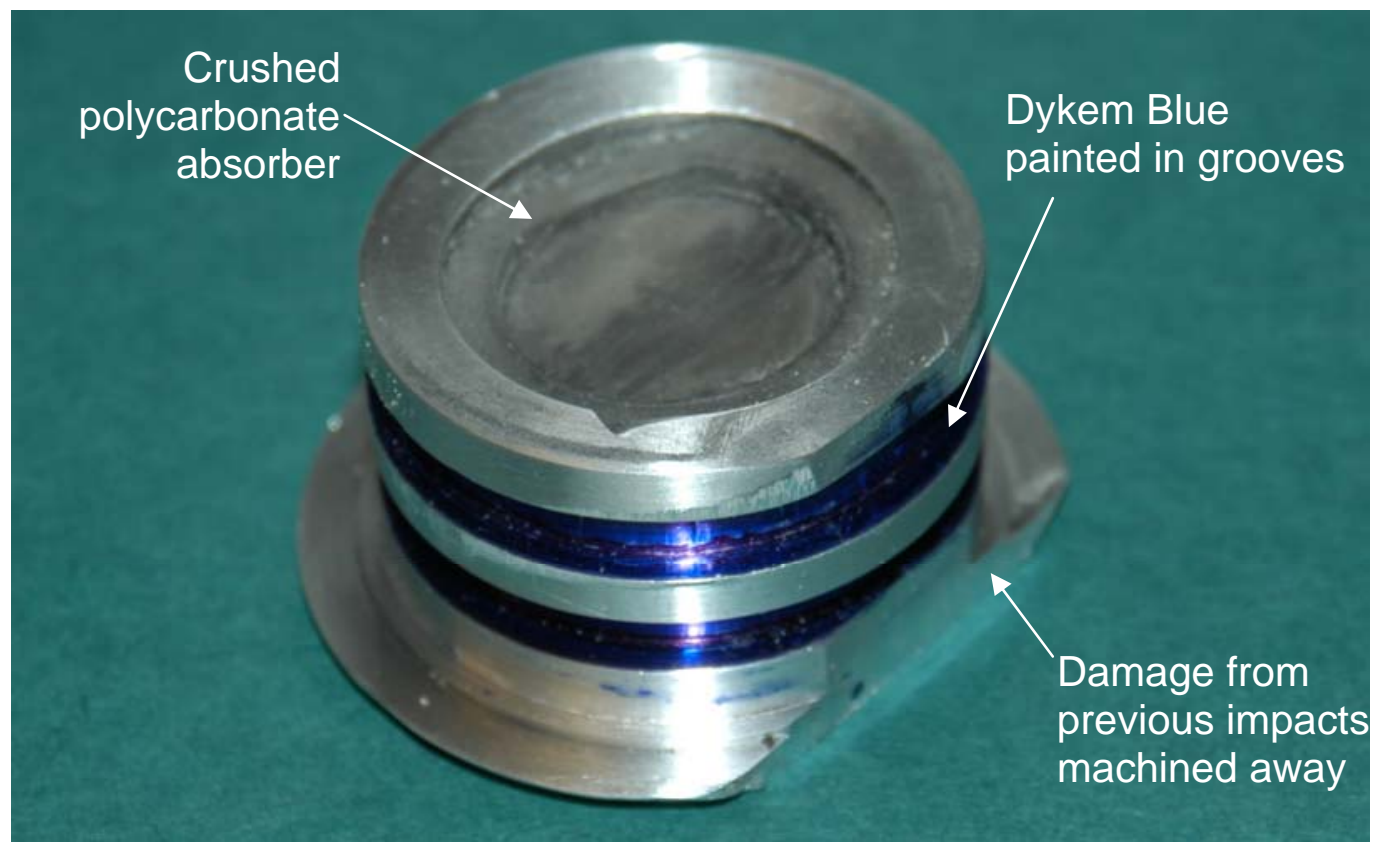

Figure 6. Post test picture of target and absorber.

The optical displacement detector worked by measuring changes in laser light reflection as grooves in the target passed in front of the detector. The resulting data approximated a square wave. Inaccuracies of the system could cause the rising characteristics to differ from the falling characteristics of the wave form. To eliminate this source of error, the delta time was determined for rising slope to rising slope and for falling slope to falling slope, as shown in Figure 7. The rising slope data was compared with the falling slope data to determine if the target had achieved constant velocity. There were no acceleration trends revealed in this comparison. The delta time was measured across constant amplitude. To avoid potential inaccuracies associated with transitioning into or out of a groove, two different amplitudes were used: near the baseline and near the midpoint. For detector 1 from shot 4 shown in figure 7, delta times were determined between: tag0-tag1, tag2-tag3, tag4-tag5, and tag6-tag7. The band width of the detectors was 
$150 \mathrm{MHz}$ which were recorded at a sample rate $1.25 \mathrm{GHz}$. The error associated with detector sampling and bandwidth was much less than $0.01 \%$. Velocities for these delta times were calculated and averaged. The groove dimensions were initially measured at the time of manufacture. During the first three shots, the target sustained damage. The groove dimensions were re-measured prior to shot 4 using digital calipers. The accuracy of the calipers was verified within 0.001 in by measuring a calibrated reference. The dimensional changes of the projectile resulted in less than $2.5 \%$ effect on calculated velocity. The averaged velocities for each optical detector and each shot are shown in Table 2 below.

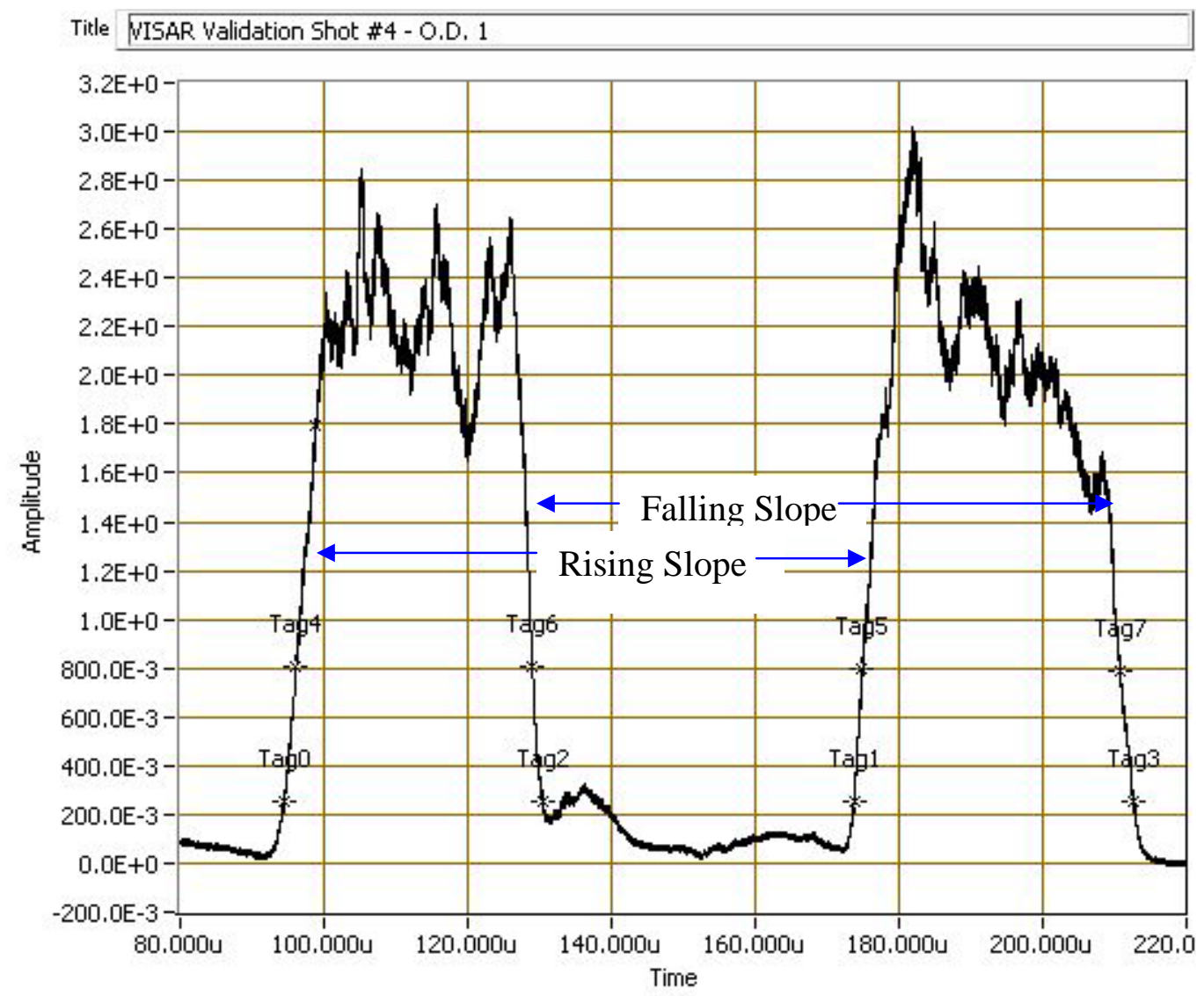

Figure 7. Typical data from optical detector. 
Table 2. Optical displacement detector velocity data

\begin{tabular}{|l|c|c|}
\hline & Detector Average (m/s) & Shot Average (m/s) \\
\hline \multicolumn{2}{|c|}{ Shot 2 } \\
\hline Detector 1 & 105.7 & \multirow{2}{*}{107.4} \\
\hline Detector 2 & 109.1 & \multirow{2}{*}{ Shot 4 } \\
\hline \multicolumn{2}{|c|}{119.0} \\
\hline Detector 1 & 118.2 & \\
\hline Detector 2 & 119.9 & \\
\hline
\end{tabular}

Target velocity was measured with the facility VISAR system. The data was initially reduced using the original fringe constant of $100 \mathrm{~m} / \mathrm{s} /$ fringe resulting in poor agreement with the optical displacement detector data. Using the detector data, a new fringe constant of $123 \mathrm{~m} / \mathrm{s} /$ fringe was calculated. The VISAR velocity was re-calculated using the new fringe constant. The VISAR data is shown in Figure 8 and Figure 9 for shots 2 and 4 respectively. The velocity was averaged over the time region shown in these figures. Although the data shows some mechanical ringing of the target, the velocity remains fairly constant. A comparison of the average VISAR data and average optical displacement detector data is made in Table 3.

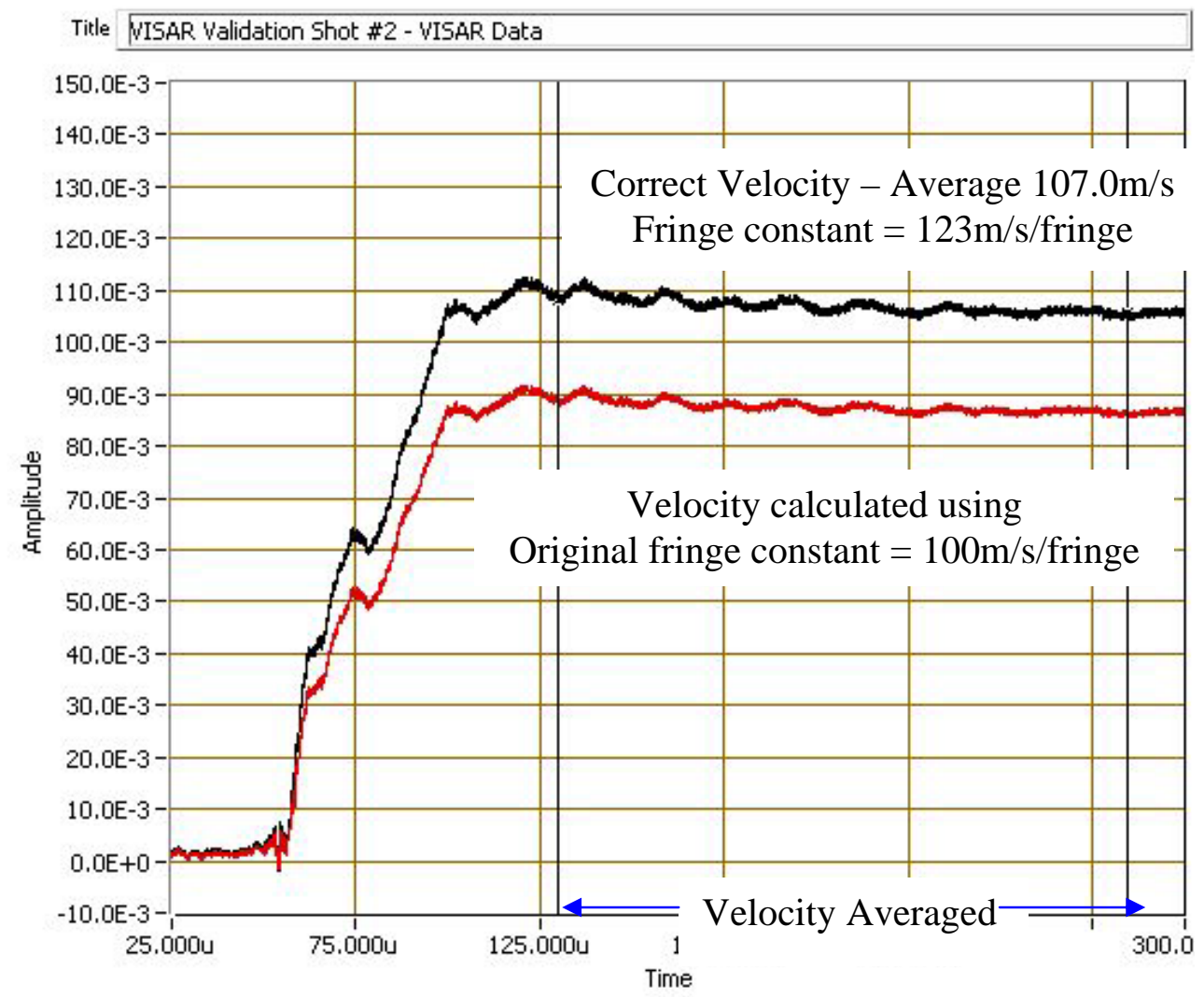

Figure 8. VISAR velocity for shot 2. 


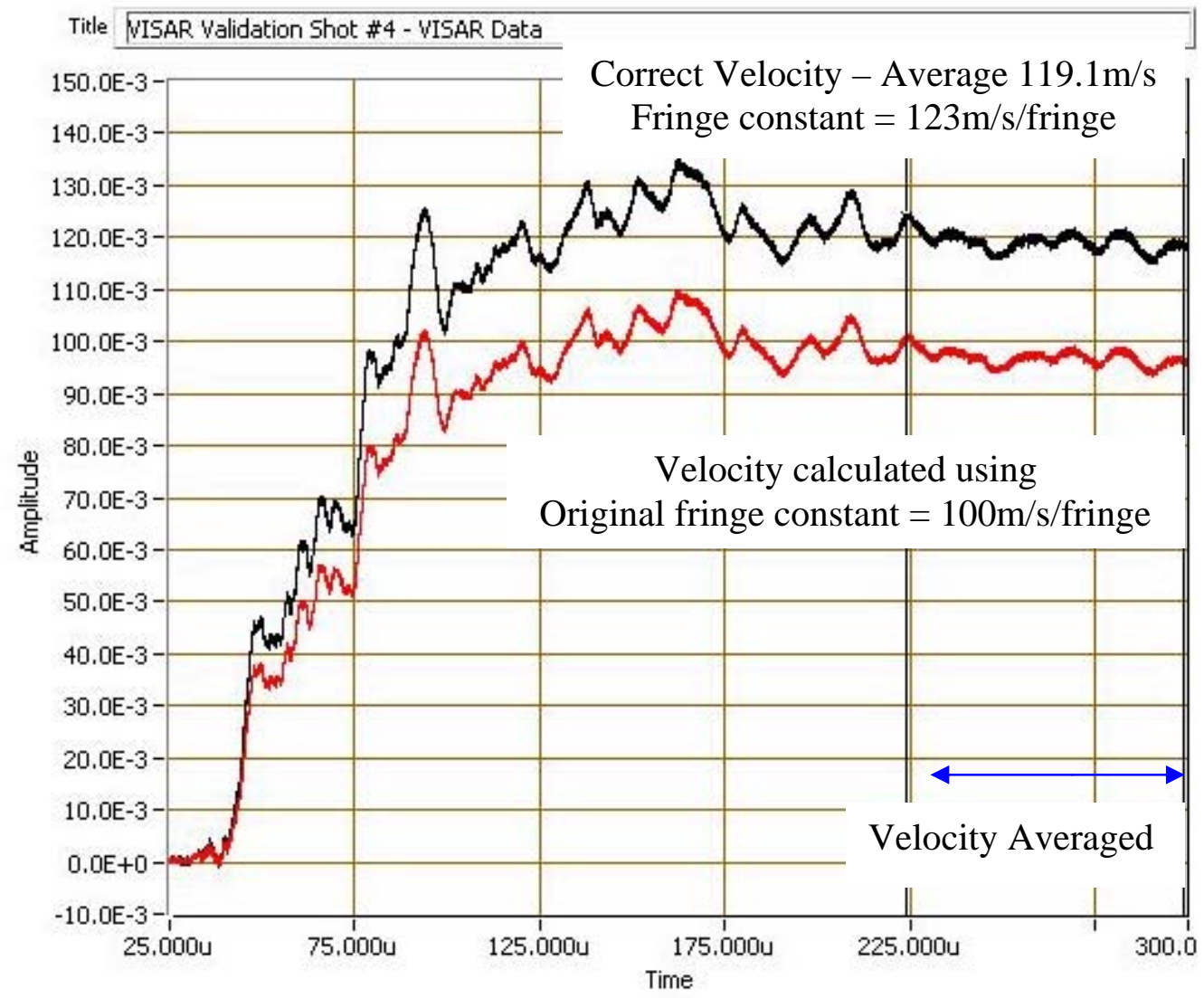

Figure 9. VISAR velocity for shot 4.

Table 3. VISAR velocity comparison to optical displacement detector velocity.

\begin{tabular}{|c|c|c|}
\hline & $\begin{array}{c}\text { Average Optical Displacement } \\
\text { Detector Velocity (m/s) }\end{array}$ & $\begin{array}{c}\text { Average VISAR velocity using } \\
123 \mathrm{~m} / \mathrm{s} / \text { fringe constant }(\mathrm{m} / \mathrm{s})\end{array}$ \\
\hline Shot 2 & 107.4 & 107.0 \\
\hline Shot 4 & 119.0 & 119.1 \\
\hline
\end{tabular}

Since the target was accelerating away from the VISAR probe, the light return to the VISAR was also decreasing. To ensure there was sufficient light return during the target acceleration, light intensity was measured. Figure 10 shows VISAR light return remains fairly constant until a constant target velocity is achieved. Figure 10 confirms the nearly constant velocity was not an artifact of insufficient light. 


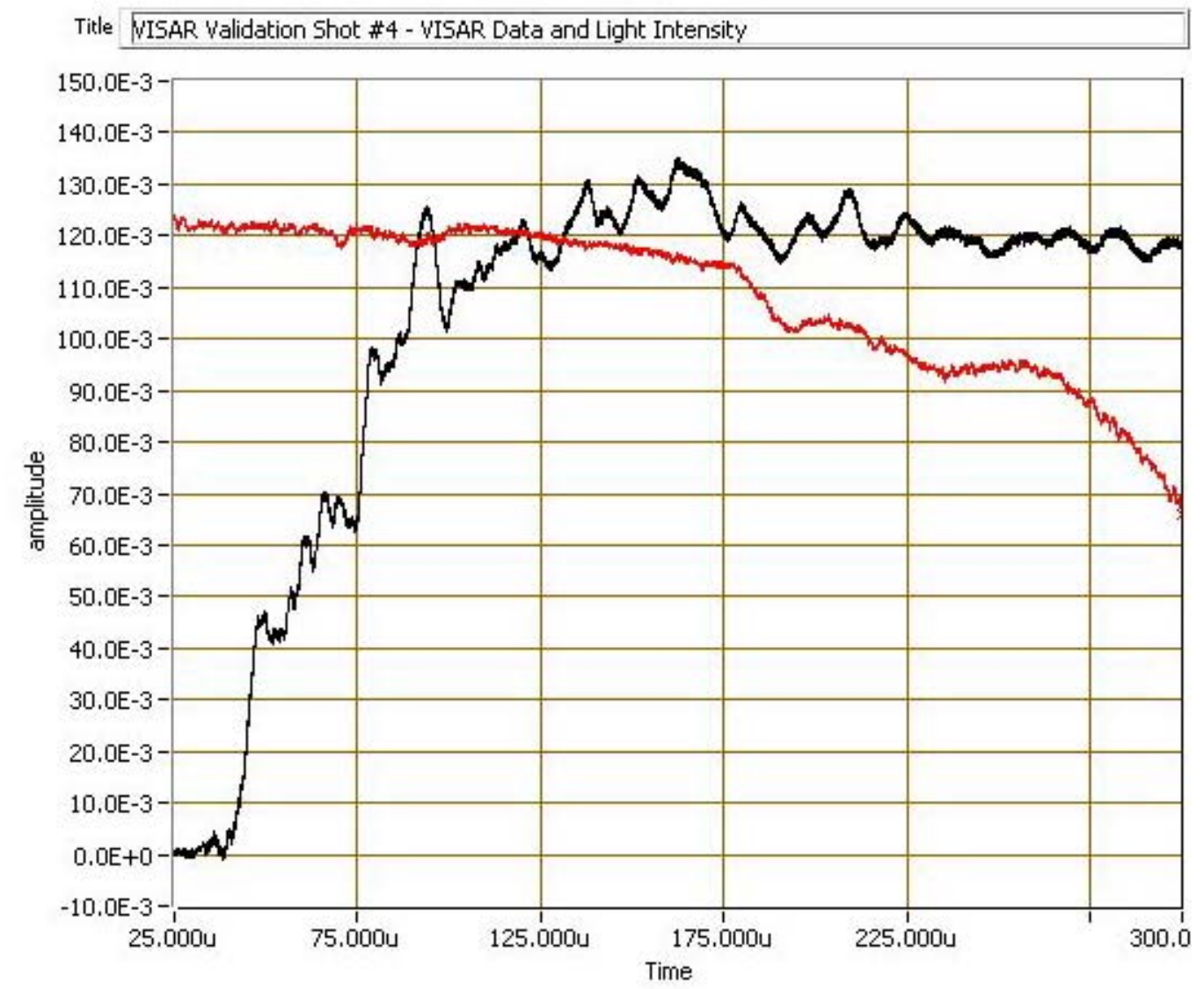

Figure 10. VISAR data overlay with light intensity monitor. (Note: intensity data scaled and inverted.)

The initial position of the target prior to impact was configured with the optical displacement detector near the leading edge of the first groove. Consequently the target moved a maximum of $5 \mathrm{~mm}$ before the detector measured the first change in light reflection, shown as the rising slope in Figure 7. The VISAR data was integrated to obtain target displacement. This integration revealed after $5 \mathrm{~mm}$ of motion, the velocity was nearly constant as shown in Figure 11. Since the optical detector's first data point was measured at approximately $5 \mathrm{~mm}$ displacement and the VISAR integration indicated nearly constant velocity after $5 \mathrm{~mm}$, the optical detector data was collected at relatively constant velocity. 


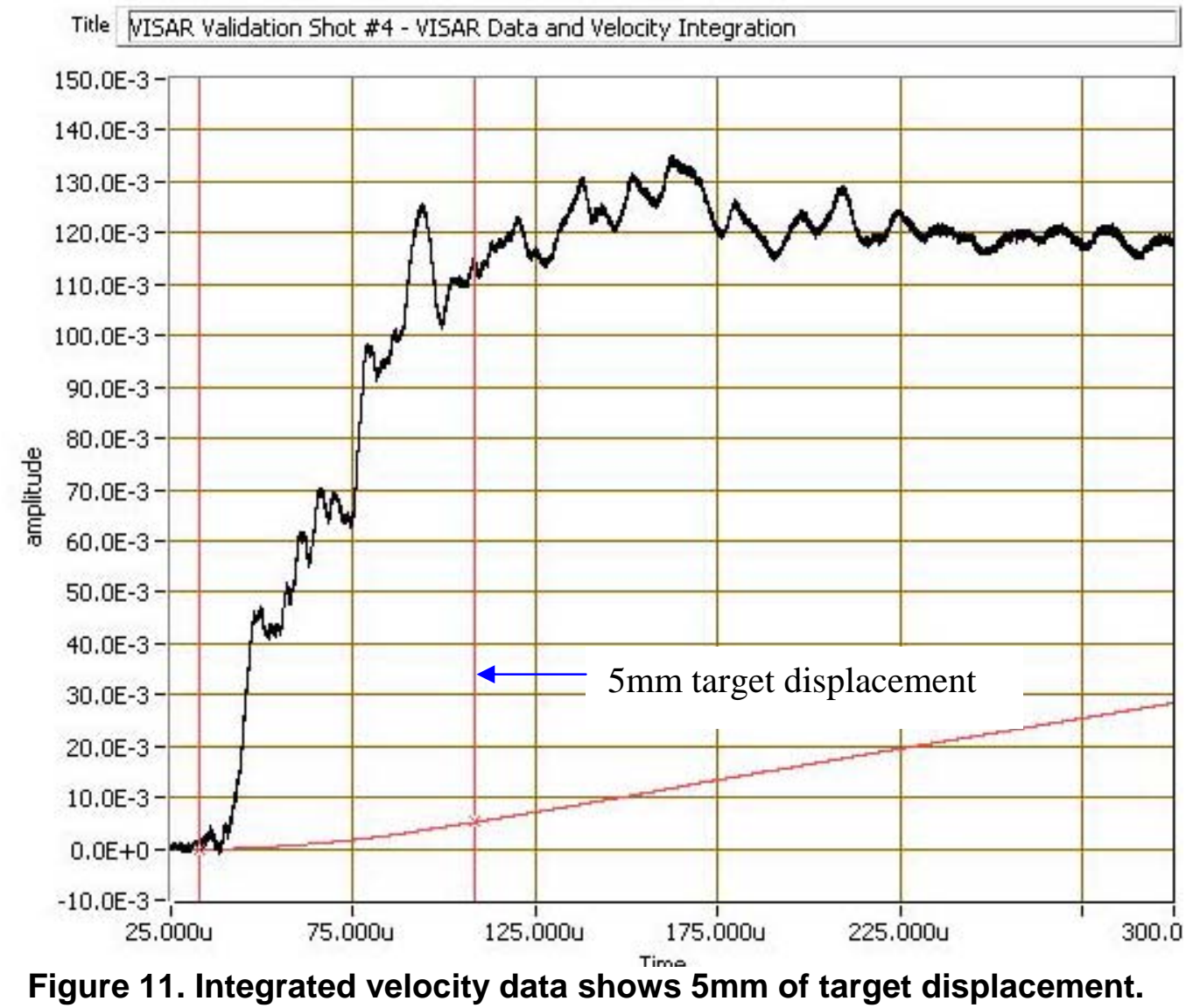

For test two, the gun was pressurized to 570psi. As shown in Table 1, 570psi was predicted to result in a target velocity of $150 \mathrm{~m} / \mathrm{s}$. For test four, the gun was pressurized to $900 \mathrm{psi}$ which resulted in a target velocity prediction of $200 \mathrm{~m} / \mathrm{s}$. Table 3 shows a measured target velocity of $107 \mathrm{~m} / \mathrm{s}$ and $119 \mathrm{~m} / \mathrm{s}$ for shots 2 and 4 respectively. These velocities were lower than predicted due to a couple of possible reasons. The KOWIN model was a simple one dimensional model. However after impact, the crushing polycarbonate absorber expanded radially absorbing energy and causing some deformation of the aluminum target. The KOWIN model also assumed the absorber was free to separate from the target and travel at a different velocity. The plastically deformed absorber was bound in the target. The resulting velocity of their combined mass was slower than the predicted velocity of the target alone. Although the velocities achieved were different than predicted, the velocities were still adequate to validate the VISAR fringe constant. The VISAR velocity was validated against an independent measure of velocity and not validated against the velocity prediction. 


\section{CONCLUSIONS}

Based on the data taken in this VISAR validation test series, the fringe constant for the facility VISAR system is $123 \mathrm{~m} / \mathrm{s} /$ fringe. Although only two data shots were successfully completed, the VISAR delay bar specification (100m/s/fringe) was found to be conclusively incorrect. Using the new fringe constant, the VISAR data is in excellent agreement with the velocities calculated from the optical displacement detector data, within $2 \%$.

VISAR systems are generally not calibrated. The fringe constant for a fixed cavity system is usually calculated from the index of refraction of the glass used in the delay bar, length of the delay bar, as well as the length of any air delay standoff. However in the LIHE VISAR system, the certification or pedigree of the delay bar optics was not available from the supplier. In this case, it was critically important to determine the fringe constant experimentally. Use of the gas gun was a useful tool to determine this key parameter.

Based on the new VISAR fringe constant determined by this validation test series, the XFlyer Phase I test series VISAR data was re-reduced greatly improving the agreement between measured data and model predictions. The approximate average correlation between X-flyer velocity and model prediction improved from within $18 \%$ to within $2 \%$. 


\section{REFERENCES}

1.Sandoval, Daniel, Gas Gun Velocity vs. Pressure, email, December 2006. 


\section{APPENDIX A: HARDWARE ENGINGEERING DRAWINGS}

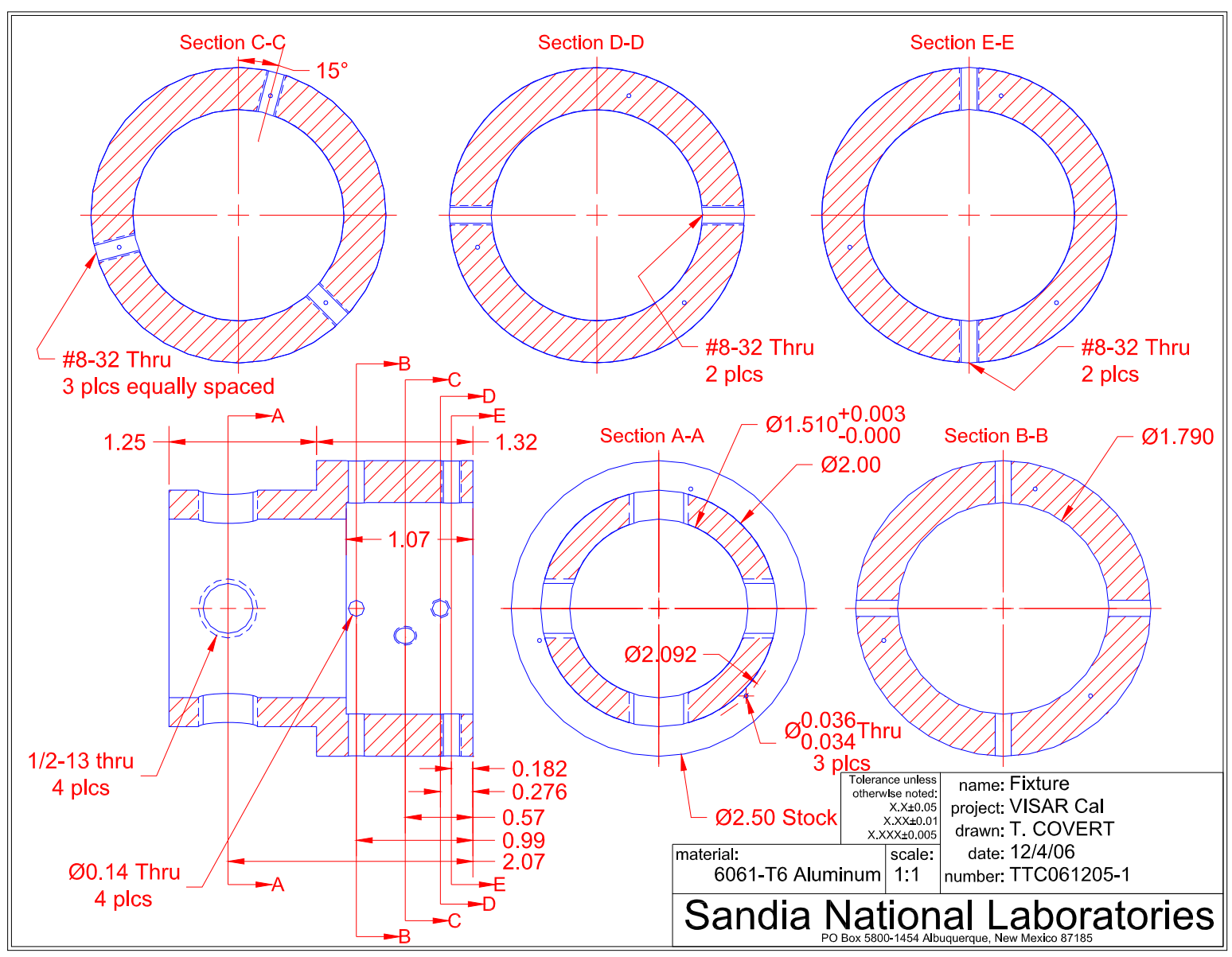




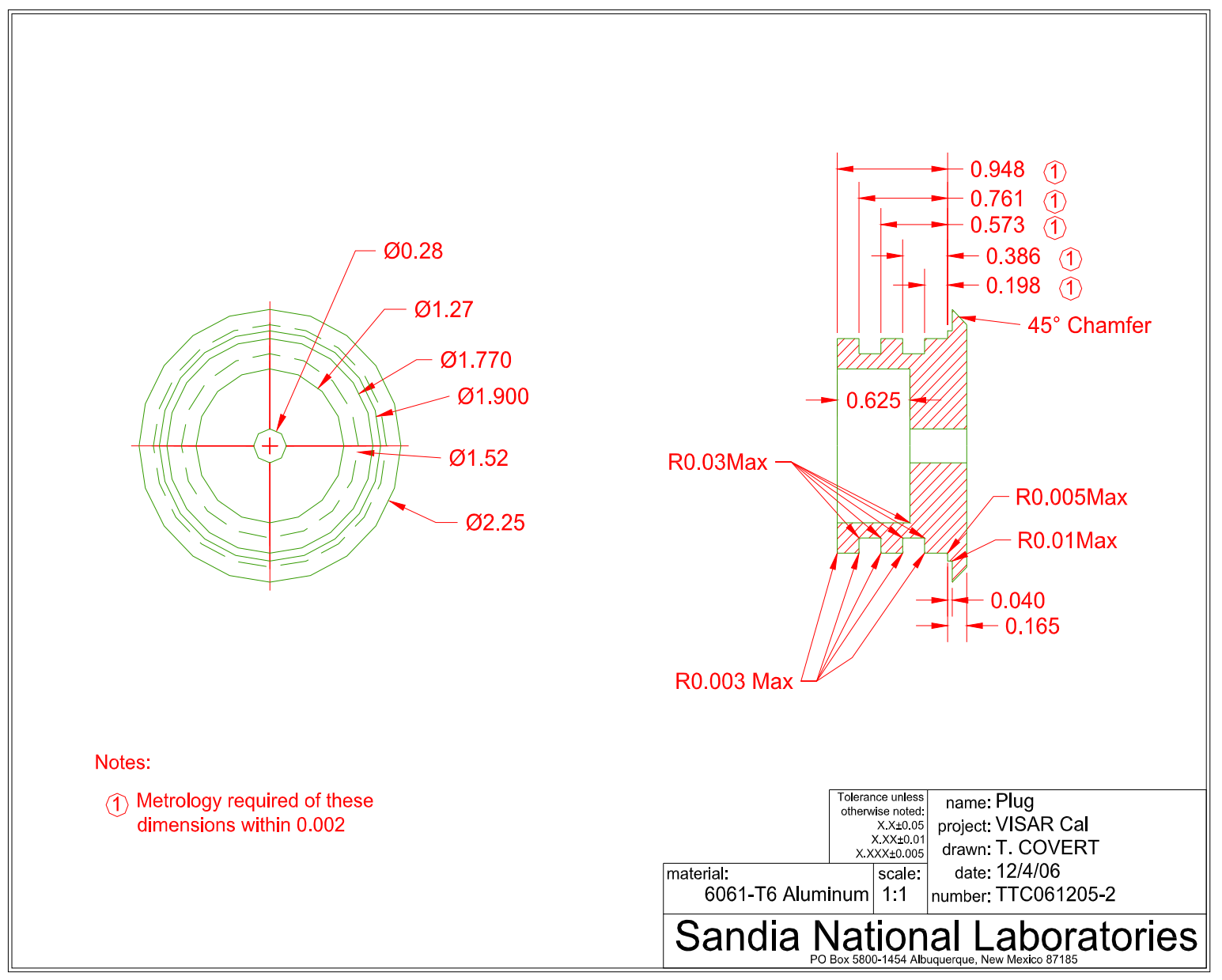




\section{DISTRIBUTION}

$\begin{array}{llll}1 & \text { MS0481 } & \text { Brad Boswell } & 2137 \\ 1 & \text { MS1454 } & \text { Mark Garrett } & 2554 \\ 3 & \text { MS1454 } & \text { Timothy Covert } & 2554 \\ 1 & \text { MS1454 } & \text { W. Gary Rivera } & 2554 \\ 1 & \text { MS1454 } & \text { Edward Mulligan } & 2554 \\ 1 & \text { MS1454 } & \text { Daniel Dow } & 2554 \\ 1 & \text { MS1454 } & \text { John Liwski } & 2554 \\ 1 & \text { MS1454 } & \text { Kevin Fleming } & 2554 \\ 1 & \text { MS1454 } & \text { Daniel Sandoval } & 2554 \\ & & & \\ 2 & \text { MS9018 } & \text { Central Technical Files } & 8944 \\ 2 & \text { MS0899 } & \text { Technical Library } & 4536\end{array}$




\section{Sandia National Laboratories}

